\title{
Modelling the effects of the sterile insect technique applied to Eldana saccharina Walker in sugarcane
}

\author{
L Potgieter* $\quad$ JH van Vuuren ${ }^{\dagger} \quad$ DE Conlong ${ }^{\ddagger \S}$
}

Received: 26 July 2011; Revised: 4 October 2011; Accepted: 19 October 2011

\begin{abstract}
A mathematical model is formulated for the population dynamics of an Eldana saccharina Walker infestation of sugarcane under the influence of partially sterile released insects. The model describes the population growth of and interaction between normal and sterile E.saccharina moths in a temporally variable, but spatially homogeneous environment. The model consists of a deterministic system of difference equations subject to strictly positive initial data. The primary objective of this model is to determine suitable parameters in terms of which the above population growth and interaction may be quantified and according to which E.saccharina infestation levels and the associated sugarcane damage may be measured. Although many models have been formulated in the past describing the sterile insect technique, few of these models describe the technique for Lepidopteran species with more than one life stage and where F1-sterility is relevant. In addition, none of these models consider the technique when fully sterile females and partially sterile males are being released. The model formulated is also the first to describe the technique applied specifically to E.saccharina, and to consider the economic viability of applying the technique to this species. Pertinent decision support is provided to farm managers in terms of the best timing for releases, release ratios and release frequencies.
\end{abstract}

Key words: Population dynamics, Eldana saccharina Walker, pest control, sterile insect technique.

\section{Introduction}

The stalk borer, Eldana saccharina Walker (Lepidoptera: Pyralidae), has been a serious pest in sugarcane plantations in South Africa since 1971. Infestation typically results in serious losses in sucrose production, not only affecting the sucrose content of sugarcane, but also the final sugarcane biomass [9]. The Eldana problem is thus of major concern

\footnotetext{
* Department of Logistics, University of Stellenbosch, Private bag X1, Matieland, 7602, South Africa.

${ }^{\dagger}$ Corresponding author: (Fellow of the Operations Research Society of South Africa), Department of Logistics, University of Stellenbosch, Private Bag X1, Matieland, 7602, South Africa, email: vuuren@sun.ac.za.

${ }^{\ddagger}$ Department of Conservation Ecology and Entomology, University of Stellenbosch, Private Bag X1, Matieland, 7602, South Africa.

${ }^{\S}$ South African Sugarcane Research Institute, Private Bag X02, Mount Edgecombe, KwaZulu-Natal, 4300, South Africa.
} 
among sugarcane farmers, and a means of effectively managing the pest is the subject of a number of intensive research programmes at the South African Sugar Research Institute (SASRI). One of the more recent research programmes is the Sterile Insect Technique (SIT), a birth control method implemented via the release of large numbers of sterile insects as part of SASRI's area-wide integrated pest management program (AW-IPM) [19]. Two pilot sites near Eston in KwaZulu-Natal have been identified as areas where the SIT project will be conducted.

E.saccharina is indigenous to Africa and occurs naturally in wetland sedges and indigenous grasses. Evidence suggests that E.saccharina infestation of sugarcane is a result of the attractive egg-laying sites (dead leaf material) [2]. The physiological development of E.saccharina is typical of insects - its lifecycle consisting of eggs, larvae, pupae and moths $[3,4,9,24,39]$. The time spent in each stage of the lifecycle is variable, depending as much on the quality of food as on the temperature experienced [4, 24, 44], with variation in development time between individuals of the same cohort. As a result of individual variation in development time, generations completely overlap with all stages in the life cycle typically present at all times [4].

Larvae hatching from the eggs disperse from the oviposition sites and feed initially on cane leaves and under leaf sheaths on organic matter. When the larvae are sufficiently robust, they start boring into the stalk and feed on the internal tissues causing yield losses in sugarcane $[2,9]$. Studies have shown that a reduction in the sucrose content of sugarcane is strongly correlated with damage levels due to E.saccharina infestation, which also impacts negatively on the final sugarcane biomass [4, 20, 27, 28, 45]. Crop and sucrose losses incurred as a result of E.saccharina infestation have been estimated at approximately $1 \%$ loss in recoverable sucrose for every $1 \%$ internodes bored [27]. Young larvae experience difficulty in penetrating sugarcane stalks; therefore, softer sugarcane varieties are often more infested than the harder varieties [3, 9]. The length of cane damaged by individual larvae is very variable, but between 2 and $8 \mathrm{~cm}$ of feeding is required to produce a mature individual [2].

According to a study by Walton [43], male and female E.saccharina moths are able to mate more than once under controlled laboratory conditions. The maximum number of matings observed per female was three, whereas the maximum number of matings observed per male was six. The majority of females mated only once, whereas the majority of males mated two to three times. E.saccharina breeds continuously throughout the year. However, seasonal cycles are still observed since particular life stages dominate in different parts of each season. Harvesting of cane is considered the largest mortality factor of E.saccharina in sugarcane; natural enemies are not considered a relevant factor [4].

Various control methods, including chemical control [22], crop management [46, 10, 12, 29], varietal resistance $[24,26]$, biological control $[13,14,15,16]$ and more recently habitat management [17] and SIT, have been proposed for the control of E.saccharina in sugarcane. Research projects on E.saccharina physiology and its behaviour after sterilisation are being conducted at SASRI and at Stellenbosch University. Invaluable insights into the mortality, levels of sterility [43] and competitivity in matings of the sterile insects [31] for different radiation doses have been gained in these projects. As with most lepidopteran species, E.saccharina requires high doses of radiation compared to other insects (approximately 


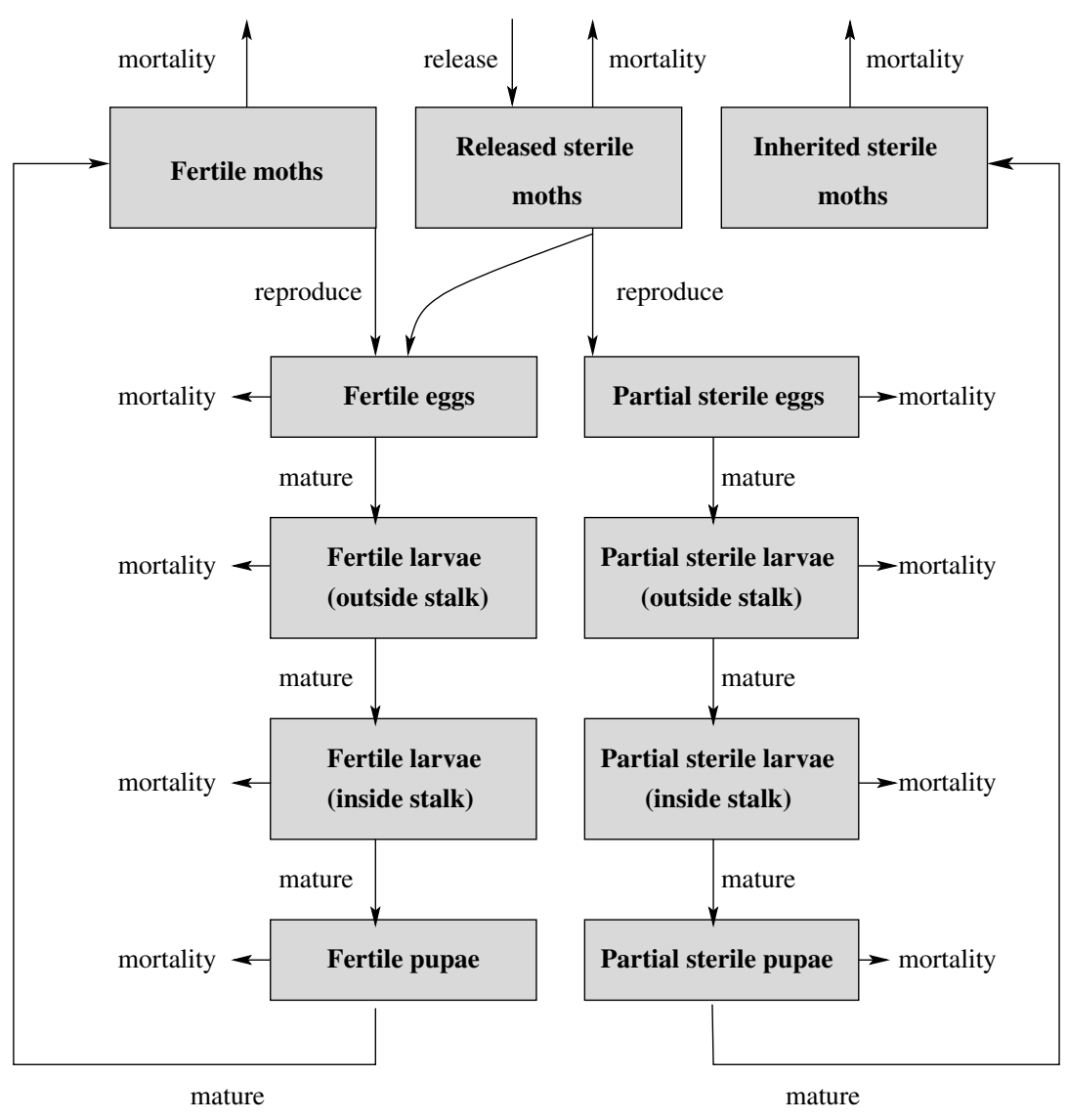

Figure 1: Model of E.saccharina life cycle with sterile releases [36].

400 Gy) in order to induce 100\% sterility. Physiological damage is often the result of high doses of radiation which, in turn, affects the competitive ability of released sterile insects compared to their wild counterparts. It has been observed, however, that considerably lower doses of radiation induce partial sterility in male moths and $100 \%$ sterility in female moths without debilitating the moths [37]. Low radiation doses do appear to have a negative effect on the competitive ability of E.saccharina females, with males remaining equally competitive [31]. The $F_{1}$ progeny of the partially sterile males (irradiated with sub-sterilizing doses) inherit semi- to complete sterility with the level of sterility of progeny higher than that of the irradiated parent [33, 37]. The sterile $F_{1}$ progeny of irradiated males has also been observed to be male-biased, with males more sterile than females [33]. As a result of the SIT research on E.saccharina, it is possible to raise large numbers of sterile E.saccharina in a laboratory exhibiting the necessary traits to be able to survive and mate. These laboratory-reared insects may then be released into native populations.

Careful and extensive scientific studies should be carried out before any natural system is altered by external manipulation, such as biological pest control or SIT, in order to avoid wasting time, money, effort and possibly altering the system into an undesirable ecological stable state [32]. In order to suppress or eradicate a pest, typical SIT questions raised are what the necessary numbers of sterile insects to release are, how frequent releases should be and whether it is an economically viable control measure. The primary objective in this 
paper is to aid the current South African SIT research effort in answering these questions via the use of a mathematical model for studying the possible effects of artificial SIT interference in native E.saccharina populations. Suitable parameters are determined in terms of which E.saccharina population growth and interaction may be quantified and according to which E.saccharina infestation levels and the associated sugarcane damage may be measured.

The model in this paper builds on previous mathematical modelling work by Hearne et al. [21] and Horton et al. [25], and describes the population dynamics of a wild E.saccharina population under the influence of a release of fully sterile females and semi-sterile males. The model is discrete and deterministic, and comprises a system of difference equations representing the change in population growth over time. Eleven subpopulations are considered, namely the fertile egg population, the inherited sterile egg population, the newly hatched fertile larvae population outside the stalk, the newly hatched inherited sterile larvae population outside the stalk, the fertile larvae population inside the stalk, the inherited sterile larvae population inside the stalk, the fertile pupae population, the inherited sterile pupae population, the fertile moth population, the inherited sterile moth population and the released sterile moth population. Promotions from stages occur at certain rates, namely the maturation rate and the mortality rate (see Figure 1). Each stage is equipped with temperature-dependent maturation and mortality rates.

\section{Modelling approach}

An E.saccharina population is considered in its various stages within a closed spatial domain, which, in the context of this study, is assumed to be a sugarcane field infested according to a uniform distribution of E.saccharina across the field.

\section{$2.1 \quad$ The model}

Let $E_{1}(t), E_{2}(t), E_{3}(t), E_{4}(t), E_{5}(t), E_{6}(t), E_{7}(t), E_{8}(t), E_{9}(t), E_{10}(t)$ and $E_{11}(t)$ denote the population densities (measured in e/100s ${ }^{1}$ ) of the eleven subpopulations mentioned above at time $t \in[0,1, \ldots, \infty)$, respectively. Define $\underline{E}(t)=\left[E_{1}(t), \ldots, E_{11}(t)\right]^{T}$. Furthermore, assume that the change in the population density of the $i$-th subpopulation per time unit in the field is equal to the amount of the $i$-th subpopulation created per time unit. Then the dynamics of the E.saccharina fertile and sterile subpopulations in the various stages may be modelled by means of the temporally discrete reaction equation

$$
\underline{E}(t+1)-\underline{E}(t)=\underline{f}(t, \underline{E})
$$

where $\underline{f}(t, \underline{E})=\left[f_{1}(t, \underline{E}), \ldots, f_{11}(t, \underline{E})\right]^{T}$ contains as its $i$-th entry the number of the $i$-th subpopulation created during time $t$. Furthermore, the system of eleven reaction terms is

\footnotetext{
${ }^{1}$ The number of members of the subpopulation per 100 stalks.
} 
given by

$$
\begin{aligned}
f_{1}(t, \underline{E}) & =0.5\left(\gamma(t) \lambda_{f}+\beta \rho(t) \lambda_{s}\right) E_{9}(t)-\left(\mu_{E}(t, \tau)+\alpha_{E}(t, \tau)\right) E_{1}(t) \\
f_{2}(t, \underline{E}) & =0.5(1-\beta) \rho(t) \lambda_{s} E_{9}(t)-\left(\mu_{E}(t, \tau)+\alpha_{E}(t, \tau)\right) E_{2}(t) \\
f_{3}(t, \underline{E}) & =\alpha_{E}(t, \tau) E_{1}(t)-\left(\mu_{L_{1}}(t, \tau)+\alpha_{L_{1}}(t, \tau)\right) E_{3}(t) \\
f_{4}(t, \underline{E}) & =\alpha_{E}(t, \tau) E_{2}(t)-\left(\mu_{L_{1}}(t, \tau)+\alpha_{L_{1}}(t, \tau)\right) E_{4}(t) \\
f_{5}(t, \underline{E}) & =\alpha_{L_{1}}(t, \tau) E_{3}(t)-\left(\mu_{L_{2}}(t, \tau)\left(1+b(t)\left(\left(E_{5}+E_{6}\right)(t)\right)\right)+\alpha_{L_{2}}(t, \tau)\right) E_{5}(t) \\
f_{6}(t, \underline{E}) & =\alpha_{L_{1}}(t, \tau) E_{4}(t)-\left(\mu_{L_{2}}(t, \tau)\left(1+b(t)\left(\left(E_{5}+E_{6}\right)(t)\right)\right)+\alpha_{L_{2}}(t, \tau)\right) E_{6}(t), \\
f_{7}(t, \underline{E}) & =\alpha_{L_{2}}(t, \tau) E_{5}(t)-\left(\mu_{P}(t, \tau)+\alpha_{P}(t, \tau)\right) E_{7}(t) \\
f_{8}(t, \underline{E}) & =\alpha_{L_{2}}(t, \tau) E_{6}(t)-\left(\mu_{P}(t, \tau)+\alpha_{P}(t, \tau)\right) E_{8}(t) \\
f_{9}(t, \underline{E}) & =\alpha_{P}(t, \tau) E_{7}(t)-\mu_{M}(t, \tau) E_{9}(t) \\
f_{10}(t, \underline{E}) & =\alpha_{P}(t, \tau) E_{8}(t)-\mu_{M}(t, \tau) E_{10}(t) \\
f_{11}(t, \underline{E}) & =r(t)-\mu_{S}(t, \tau) E_{11}(t)
\end{aligned}
$$

where $\lambda_{f}$ and $\lambda_{s}$ denote the egg laying rates of a fertile female mated with a fertile and released male, respectively, $\gamma(t)$ and $\rho(t)$ denote the probabilities of a fertile egg being fertilized by a fertile or semi-sterile sperm at time $t$, respectively, $\mu_{E}(t, \tau), \mu_{L_{1}}(t, \tau)$, $\mu_{L_{2}}(t, \tau), \mu_{P}(t, \tau), \mu_{M}(t, \tau)$ and $\mu_{S}(t, \tau)$ denote stage-specific mortality rates at time $t$ and at a temperature of $\tau$ degrees of the egg, larval, pupal and moth subpopulations, respectively. Furthermore, $b(t)$ denotes the density-dependent mortality parameter at time $t$ and $\alpha_{E}(t, \tau), \alpha_{L_{1}}(t, \tau), \alpha_{L_{2}}(t, \tau)$ and $\alpha_{P}(t, \tau)$ denote the egg, larval and pupal maturation rates at time $t$ and at a temperature of $\tau$ degrees, respectively, while $r(t)$ denotes the sterile release rate at time $t$. Here, $\beta$ denotes the fraction of eggs from the $F_{1}$ progeny of released sterile males which is fertile. Finally, the initial conditions $E_{1}(0)=e_{1}$, $E_{2}(0)=0, E_{3}(0)=e_{3}, E_{4}(0)=0, E_{5}(0)=e_{5}, E_{6}(0)=0, E_{7}(0)=e_{7}, E_{8}(0)=0$, $E_{9}(0)=e_{9}, E_{10}(0)=0$ and $E_{11}(0)=0$ are prescribed, where $e_{1}, e_{3}, e_{5}, e_{7}$ and $e_{9}$ are assumed to be positive real numbers.

In order to be able to compare solutions of a variety of different scenarios in terms of initial conditions, equation (1) has to be expressed in terms of non-dimensional variables. If we let

$$
\mathcal{E}_{j}(t)=\frac{E_{j}(t)}{E_{j}(0)} \text { and } \mathcal{E}_{i}(t)=E_{i}(t)
$$

for all $i=2,4,6,8,10,11$ and all $j=1,3,5,7,9$, where $E_{j(0)}$ denotes the initial fertile population densities at time $t=0$, then the non-dimensionalised model equations are

$$
\mathcal{E}_{i}(t+1)-\mathcal{E}_{i}(t)=f_{i}\left(t, \mathcal{E}_{i}(t) \frac{E_{j}(0)}{E_{i}(0)}\right)
$$


for $i=1,3,5,7,9$ and $j=1,3,5,7,9$, and

$$
\mathcal{E}_{i}(t+1)-\mathcal{E}_{i}(t)=f_{i}\left(t, \mathcal{E}_{i}(t)\right)
$$

for $i=2,4,6,8,10,11$.

\section{$2.2 \quad$ Initial values}

In order to obtain the equilibrium ratios of the system (1), the time-dependent variables $E_{i}(t)$ may be substituted by time-independent variables $E_{i}\left(t^{*}\right)$, solving the resulting equations simultaneously [36]. The initial relations between egg, larval, pupal and moth densities are assumed to satisfy the ratios

$$
\frac{\lambda_{f}}{\mu_{E}+\alpha_{E}}: \frac{\lambda_{f} \alpha_{E}}{\left(\mu_{E}+\alpha_{E}\right)\left(\mu_{L_{1}}+\alpha_{L_{1}}\right)}: \frac{\mu_{M}\left(\mu_{P}+\alpha_{P}\right)}{\alpha_{L_{2}} \alpha_{P}}: \frac{\mu_{M}}{\alpha_{P}}: 1
$$

of the equilibrium population densities in the E.saccharina mean-field model.

\subsection{The probability of fertilization}

A fertile female, a released sterile female or an inherited sterile female may either mate with a fertile male, a released sterile male or an inherited sterile male. This results in nine possible mating combinations. The events of mating with a certain type of female and mating with a certain type of male are independent if it is assumed that no type of male or female has a specific preference for another type of male or female. The probability of any type of offspring occurring may therefore be calculated by multiplying the probability of mating with a certain type of female by the probability of mating with a certain type of male. Following the same approach as Berryman [5], the statistical distribution of the nine possible matings may therefore be expressed by

$$
\left(P_{f f}(t)+P_{i f}(t)+P_{r f}(t)\right)^{n}\left(P_{f m}(t)+P_{i m}(t)+P_{r m}(t)\right)^{n}=1,
$$

where $P_{f f}(t), P_{i f}(t), P_{r f}(t), P_{f m}(t), P_{i m}(t)$ and $P_{r m}(t)$ denote the probabilities of mating with a wild fertile female, an inherited sterile female, a released sterile female, a wild fertile male, an inherited sterile male and a released sterile male at time $t$, respectively, and $n$ denotes the total number of matings possible per insect.

Also, the statistical distribution of the three possible matings with a male and female may be expressed separately by

$$
\begin{aligned}
\left(P_{f m}(t)+P_{i m}(t)+P_{r m}(t)\right)^{n} & =1, \\
\left(P_{f f}(t)+P_{i f}(t)+P_{r f}(t)\right)^{n} & =1 .
\end{aligned}
$$

Since the model is only concerned with matings with a fertile female, a released sterile male and an inherited sterile male, $P_{f m}(t), P_{i f}(t)$ and $P_{r f}(t)$ may be written in terms of $P_{r f}(t), P_{i m}(t)$ and $P_{f f}(t)$ as

$$
\begin{aligned}
P_{i f}(t)+P_{r f}(t) & =1-P_{f f}(t), \\
P_{f m}(t) & =1-P_{i m}(t)-P_{r m}(t) .
\end{aligned}
$$


Furthermore, the expressions

$$
\begin{aligned}
P_{r m}(t) & =\frac{c_{m} m \mathcal{E}_{11}(t)(1-q)}{0.5 \mathcal{E}_{9}(t)+c_{m} m \mathcal{E}_{11}(t)+0.6 \mathcal{E}_{10}(t)}, \\
P_{i m}(t) & =\frac{0.6 \mathcal{E}_{10}(t)}{0.5 \mathcal{E}_{9}(t)+c_{m} m \mathcal{E}_{11}(t)+0.6 \mathcal{E}_{10}(t)}, \text { and } \\
P_{f f}(t) & =\frac{0.5 \mathcal{E}_{9}(t)+c_{f} q(1-m) \mathcal{E}_{11}(t)}{0.5 \mathcal{E}_{9}(t)+c_{f}(1-m) \mathcal{E}_{11}(t)+0.4 \mathcal{E}_{10}(t)}
\end{aligned}
$$

are assumed, where $c_{m}$ denotes the competitivity coefficient of released sterile males, $c_{f}$ denotes the competitivity coefficient of released sterile females, $q$ denotes the proportion of residual fertility within the released sterile population and $m$ denotes the male proportion in the released sterile population. An equal proportion of males and females are assumed within the wild fertile population, whereas the inherited sterile population is assumed to have a $60 \%$ male proportion. Furthermore, $m$ may either be equal to 0,1 or 0.5 , depending on whether the released insects are female only, male only, or a combination of female and male, respectively.

The expansion of the left-hand side of (3) is given by

$$
\left.\left(P_{f m}(t)+P_{i m}(t)+P_{r m}(t)\right)^{n}=\sum_{i=0}^{n} \sum_{j=0}^{n-i} \frac{n !}{i ! j !(n-i-j) !} P_{f m}(t)^{i} P_{i m}(t)^{j} P_{r m}(t)\right)^{n-i-j}
$$

A female may mate $i$ times with a fertile male, $j$ times with an inherited sterile male and $k=n-i-j$ times with a released sterile male in $n ! / i ! j ! k !$ different sequential orders. If the ability of a released sterile sperm is less than that of a wild sperm, then the probability of an egg being fertilized by a fertile sperm is $i / n$, while the probability of an egg being fertilized by a sterile sperm, given that a female has mated with both fertile and sterile males, is $\frac{k}{n} c_{s}$, where $c_{s}$ denotes the competitivity factor of released sterile sperm compared to other sperm. If a female has only mated with sterile moths, the probability of an egg being fertilized by a sterile sperm is 1 . The probabilities of any egg being fertilized by a fertile $\left(P_{f s}\right)$ and released sterile sperm $\left(P_{s s}\right)$ may then be derived as

$$
P_{f s}(t)=\sum_{n=1}^{A} F_{n}\left[1-P_{i m}(t)-\left(P_{r m}^{n}(t)+c_{s} P_{r m}(t)-c_{s} P_{r m}^{n}(t)\right)\right]
$$

and

$$
P_{s s}(t)=\sum_{n=1}^{A} F_{n}\left[P_{r m}^{n}(t)+c_{s} P_{r m}(t)-c_{s} P_{r m}^{n}(t)\right],
$$

respectively, where $F_{n}$ denotes the proportion of females mating $n$ times and where $A$ denotes the maximum number of matings per female [36].

The expansion of the left-hand side of (4) is given by

$$
\left(P_{f f}(t)+P_{s f}(t)\right)^{n}=\sum_{k=0}^{n}\left(\begin{array}{l}
n \\
k
\end{array}\right) P_{f f}(t)^{k} P_{s f}(t)^{n-k},
$$


where $P_{s f}(t)=P_{i f}(t)+P_{r f}(t)$. A general expression for the probability of any sperm fertilizing a fertile egg may therefore be derived which considers all possible mating habits (all possible values of $n$ ), and is given by

$$
\sum_{n=1}^{B} M_{n} \sum_{k=1}^{n}\left(\begin{array}{l}
n \\
k
\end{array}\right)(-1)^{k+1} P_{f f}(t)^{k},
$$

where $M_{n}$ denotes the proportion of males mating $n$ times and where $B$ denotes the maximum number of matings per male [36].

The probability of fertile offspring and inherited sterile offspring may be computed from (2) by multiplying the probability of mating with a fertile female (7) by the probability of mating with either a fertile male (5) or a released sterile male (6), respectively. The probabilities $\gamma(t)$ and $\rho(t)$ are therefore given by

$$
\begin{aligned}
& \gamma(t)=P_{f s} \sum_{n=1}^{B} M_{n} \sum_{k=1}^{n}\left(\begin{array}{l}
n \\
k
\end{array}\right)(-1)^{k+1} P_{f f}(t)^{k}, \\
& \rho(t)=P_{s s} \sum_{n=1}^{B} M_{n} \sum_{k=1}^{n}\left(\begin{array}{l}
n \\
k
\end{array}\right)(-1)^{k+1} P_{f f}(t)^{k} .
\end{aligned}
$$

The values of $A, B, F_{n}$ and $M_{n}$ are assumed to be equal to the values obtained in the study by Walton [43], and are summarised in Table 1.

\begin{tabular}{ccc}
\hline Number of matings $(n)$ & $M_{n}$ & $F_{n}$ \\
\hline 1 & 0.100 & 0.567 \\
2 & 0.233 & 0.367 \\
3 & 0.233 & 0.066 \\
4 & 0.167 & 0.000 \\
5 & 0.200 & 0.000 \\
6 & 0.067 & 0.000 \\
\hline
\end{tabular}

Table 1: The fraction of E.saccharina males $\left(M_{n}\right)$ and females $\left(F_{n}\right)$ exhibiting different mating frequencies $(n)$. The maximum number of matings per female $(A)$ is 3 and the maximum number of matings per male $(B)$ is 6 .

\subsection{Growth rate}

The number $\lambda_{f}$ of viable eggs (e/100s) laid per day per female E.saccharina moth mated with a fertile male is assumed to be 4.725 , which is consistent with the model results of Van Coller [42] and Horton [24]. According to the study by Walton [43], the number of viable eggs laid per female moth mated with a released male is only $23 \%$ of that associated with a normal fertile mating; therefore $\lambda_{s}$ is assumed to be 1.08675 . 


\subsection{Stage-specific mortality rates}

Each life stage of E.saccharina has a unique mortality rate which depends also on the daily average temperature. The Entomology Department at SASRI has, through a number of research experiments, obtained stage-specific mortality rates of E.saccharina and how changes in temperature affect these rates [24]. The stage-specific mortality rates per day at a temperature of $26^{\circ} \mathrm{C}$ are given in Table 2. Table 3 illustrates the change in mortality rate (in relation to mortality rates at a temperature of $26^{\circ} \mathrm{C}$ ) for each of the specified temperatures. The sugarcane plant's major defence against E.saccharina is to delay stalk penetration and larval activity by physico-chemical factors, both on the outside and inside of stalks. Delayed stalk penetration results in longer exposure of larvae to natural and applied mortality factors such as predation and chemical pesticides [26]. Crop varieties have different resistance levels with respect to E.saccharina infestation. The larval mortality rate is therefore multiplied by a resistance rating function $v(\omega)$ to incorporate the increase/decrease in mortality for different crop varieties, where $\omega$ denotes the resistance rating index of the crop variety [24].

\begin{tabular}{lccccc}
\hline & $\begin{array}{c}\text { eggs } \\
\left(\mu_{e}\right)\end{array}$ & $\begin{array}{c}\text { larvae } \\
\left(\mu_{l_{1}}\right)\end{array}$ & $\begin{array}{c}\text { robust larvae } \\
\left(\mu_{l_{2}}\right)\end{array}$ & $\begin{array}{c}\text { pupae } \\
\left(\mu_{p}\right)\end{array}$ & $\begin{array}{c}\text { moths } \\
\left(\mu_{m}\right)\end{array}$ \\
\hline Mortality rate (/day) & 0.03 & 0.115 & 0.009 & 0.007 & 0.2 \\
\hline
\end{tabular}

Table 2: Stage-specific mortality rates for E.saccharina at a temperature of $26^{\circ} \mathrm{C}$ [42].

\begin{tabular}{cccccc}
\hline & $10^{\circ} \mathrm{C}$ & $19^{\circ} \mathrm{C}$ & $22^{\circ} \mathrm{C}$ & $26^{\circ} \mathrm{C}$ & $30^{\circ} \mathrm{C}$ \\
\hline eggs & 0.00 & 0.64 & 0.78 & 1.00 & 1.10 \\
larvae & 0.00 & 0.58 & 0.78 & 1.00 & 1.10 \\
pupae & 0.00 & 0.44 & 0.54 & 1.00 & 1.10 \\
moths & 0.00 & 0.56 & 0.71 & 1.00 & 1.10 \\
\hline
\end{tabular}

Table 3: Collocation points for the temperature functions used to adjust mortality rates [42].

The mortality rate of each life stage at time $t$ is $\mu_{E}(t, \tau)=\mu_{e} k_{e}(\tau), \mu_{L_{1}}(t, \tau)=\mu_{l_{1}} k_{l}(\tau) v(\omega)$, $\mu_{L_{2}}(t, \tau)=\mu_{l_{2}} k_{l}(\tau) v(\omega), \mu_{P}(t, \tau)=\mu_{p} k_{p}(\tau)$ and $\mu_{M}(t, \tau)=\mu_{m} k_{m}(\tau)$, respectively, where the temperature functions $k_{e}(\tau), k_{l}(\tau), k_{p}(\tau)$ and $k_{m}(\tau)$ are determined by finding the lowest degree polynomial which achieves a satisfactory fit to the corresponding stage data in Table 3. Changes in the mortality rates $\mu_{E}(t, \tau), \mu_{L_{1}}(t, \tau), \mu_{L_{2}}(t, \tau), \mu_{P}(t, \tau)$ and $\mu_{M}(t, \tau)$ as a result of changes in temperature are shown in Figure 2.

\subsection{Density-dependent mortality}

Increasing cane age remains the main factor associated with increasing E.saccharina infestation $[11,35]$. The low nutritional content of immature sugarcane keeps the E.saccharina populations low — typically below 10 e/100s. The last few months of growth and resulting higher nutritional content in mature sugarcane, on the other hand, results in a rapid E.saccharina population increase [21]. This may be modelled by assuming a lower carrying capacity and therefore an increased E.saccharina larval density-dependent mortality during the first months of sugarcane growth, and also assuming an increased carrying capacity and therefore a decreased E.saccharina larval density-dependent mortality during 


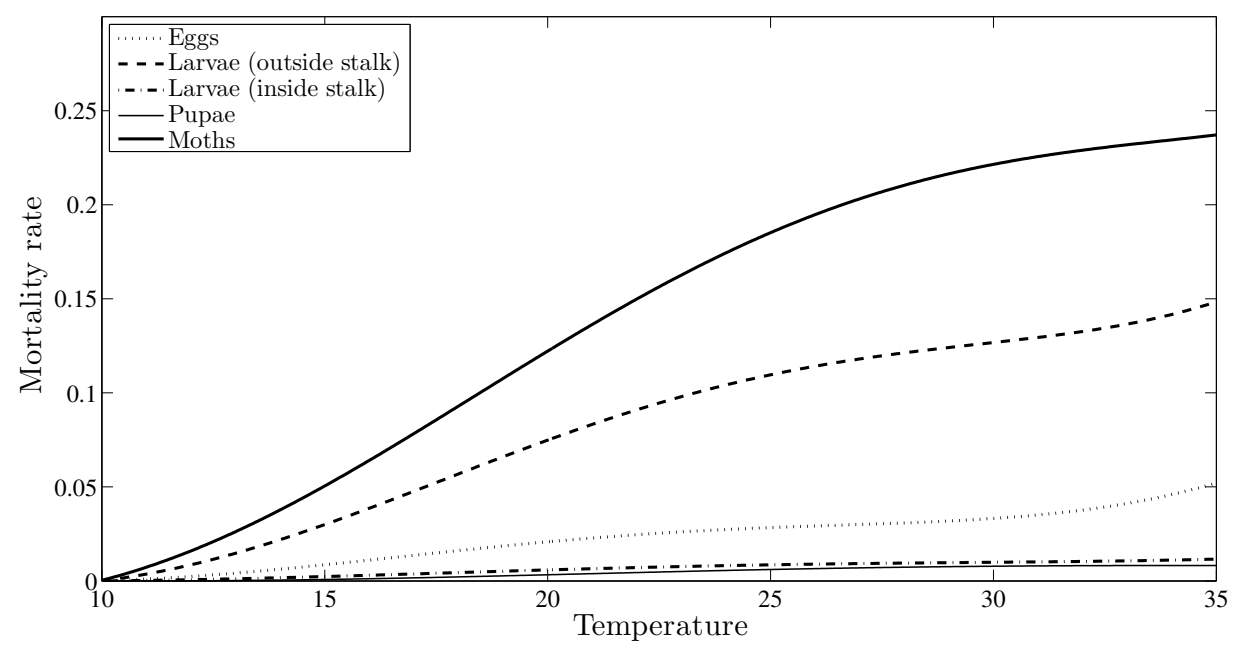

Figure 2: The temperature-dependent mortality functions $\mu_{E}(t, \tau), \mu_{L_{1}}(t, \tau), \mu_{L_{2}}(t, \tau), \mu_{P}(t, \tau)$ and $\mu_{M}(t, \tau)$.

the last few months of sugarcane growth. The value of the density-dependent parameter $b(t)$ is therefore determined by assuming a decreasing s-shaped function of the form

$$
b(t)=\frac{y}{d^{z}+1}
$$

where $y>0$ and $z>1$. In (8), $d$ denotes the expression $\frac{3}{365} a$ for a one-year growth cycle or the expression $\frac{3}{730} a$ for a two-year growth cycle, where $a$ denotes the age of the crop in days at time $t$. The factor $d$ is employed in (8) in order to scale the horizontal axis between 0 and 3 to days. For the purposes of this study, region- and farm-specific factors, such as climate, soil type and farming practices, are incorporated into the model by adjusting the values of $y$ and $z$ in (8) according to previous infestation data for the specific region or farm.

\subsection{Stage-specific maturation rates}

Maturation from each life stage of E.saccharina depends on the temperature to which the insect is exposed. Higher temperatures result in higher rates of maturation until a maximum maturation rate is reached. The development time for each stage (excluding moths) in the E.saccharina lifecycle has been calculated at various temperatures through laboratory experiments [44]. The average time to maturation for each of these temperatures are shown in Table 4 together with the corresponding maturation rates approximated by the reciprocals of the average development times [36].

The maturation rates of each specific life stage are $\alpha_{E}(t, \tau)=g_{e}(\tau), \alpha_{L_{1}}(t, \tau)=g_{l_{1}}(\tau)$, $\alpha_{L_{2}}(t, \tau)=g_{l_{2}}(\tau)$ and $\alpha_{P}(t, \tau)=g_{p}(\tau)$, respectively, where the temperature functions $g_{e}(\tau), g_{l_{1}}(\tau), g_{l_{2}}(\tau)$ and $g_{p}(\tau)$ are determined by finding the lowest degree polynomial that achieves a satisfactory fit to the corresponding stage data in Table 4 (see Figure 3 ). 


\begin{tabular}{ccccccccc}
\hline & \multicolumn{2}{c}{ Eggs } & \multicolumn{2}{c}{ Larvae (outside stalk) } & \multicolumn{2}{c}{ Larvae (inside stalk) } & \multicolumn{2}{c}{ Pupae } \\
${ }^{\circ} C$ & Days & Rate & Days & Rate & Days & Rate & Days & Rate \\
\hline 13 & 16.8 & 0.060 & & & & & & \\
15 & 13.2 & 0.076 & 85.10 & 0.01175 & 97.0 & 0.01031 & 38.0 & 0.026 \\
20 & 8.6 & 0.116 & 36.32 & 0.02753 & 50.5 & 0.01980 & 19.6 & 0.051 \\
25 & 6.1 & 0.164 & 19.40 & 0.05155 & 30.3 & 0.03300 & 9.8 & 0.102 \\
30 & 4.8 & 0.208 & 12.70 & 0.07874 & 22.9 & 0.04367 & 8.0 & 0.125 \\
35 & 4.6 & 0.217 & 14.88 & 0.06720 & 19.9 & 0.05025 & 6.1 & 0.164 \\
\hline
\end{tabular}

Table 4: Average development time (in days) per life stage measured at different temperatures [44]. The maturation rate is approximated by the reciprocal of the average development time spent in each stage.

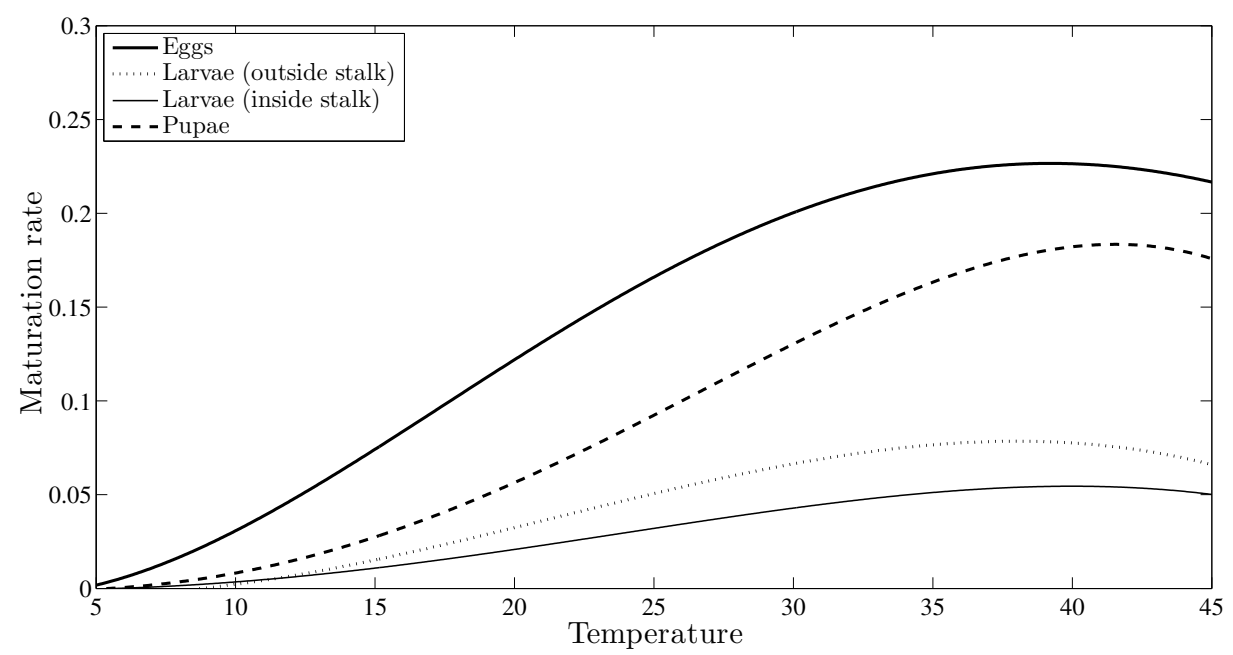

Figure 3: The lowest degree polynomials, namely fourth degree polynomials, which give a satisfactory fit to the corresponding stage maturation data [36].

\subsection{Competitivity and fertility of released insects}

According to the most recent research, the competitivity of laboratory-reared E.saccharina males is thought to be more or less the same as for their wild counterparts, and may be even higher. However, the competivity of laboratory-reared E.saccharina females seems to be affected to a large extent [31]. Females appear to be more sensitive to radiation, hence the apparent reduction in their competitiveness [31, 43]. It is therefore assumed in this paper that $c_{m}=1$ and $c_{s}=1$, unless otherwise stated. The value of $c_{f}$ is assumed equal to 0.1 , unless otherwise stated. With current technology, the fraction of residual steriles, $q$, is very close to zero and may therefore be ignored.

\subsection{Fertility of the $F_{1}$ generation}

Experiments have shown that at a radiation dose of $200 \mathrm{~Gy}$, the fraction of fertiles $(\beta)$ in the $F_{1}$ generation from wild females mating with released partially sterile males is less than 0.15 [43]. The male bias in E.saccharina is assumed to be approximately $3: 2$. 


\subsection{A release strategy}

As defined in [34], the decision variables related to a release strategy are the release ratio, $\eta$, and frequency of releases in terms of days, $\theta$. Releases are assumed to occur either daily, twice a week, weekly, two-weekly, or three-weekly. In the remainder of this paper a release strategy refers to a pair of values $(\eta, \theta)$ for both the decision variables, while an optimal release strategy is defined as a release strategy which maximises the SIT profit. In order to maximise profit, E.saccharina infestation has to be minimised as does the cost of applying SIT. An optimal strategy is obtained in this paper by means of repeated simulation runs of the model in $\S 2.1$.

\subsection{The cost of a release strategy}

In order to estimate the overall cost of a release strategy, three costs are taken into account, namely the cost $\kappa_{r}$ of raising and sterilising one Esaccharina moth, the labour cost $\kappa_{\ell}$ involved per day per hectare of releasing sterile moths, and the fuel cost $\kappa_{f}$ per hectare involved in transporting the sterilised moths on the release site. Transportion cost to a release site is not included in the cost estimation.

There are currently four SIT rearing facilities in South Africa, namely Entomon Technologies (Pty) Ltd, SIT Africa (Pty) Ltd, Xsit (Pty) Ltd and the SASRI Insect Rearing Unit, each producing different types of sterile insect species. The total cost to a farmer for applying the SIT is currently estimated at between R0.03 and R0.06 per moth released $[40,47]$. The SASRI rearing unit is still in the research phase, with limited production capacity. At the time of this study, the cost per sterile E.saccharina moth was approximately R1.00, which may reduce significantly once production is increased. In this paper $\kappa_{r}$ is assumed to range between $\mathrm{R} 0.03$ and $\mathrm{R} 0.10$.

The typical costs involved in aerial releases (which include the hiring of an aircraft, fuel and pilot fees) are quoted as US $\$ 465 / \mathrm{h}[41]$, which translates to an estimated cost ranging between R4.76 and R23.80 p/ha for a flight path spacing ${ }^{2}$ of between 100 and $500 \mathrm{~m}$ $[36,41]$. Research is still in progress with respect to finding alternative air vehicles which are more cost-effective. A recent study proposed a custom-built unmanned air vehicle (UAV) which is expected to result in major cost savings in terms of pilot fees and fuel consumption when compared to the aircraft currently used [41].

The total cost of a release strategy is

$$
C=\sum_{j=0}^{t}\left(\kappa_{r} r(j)+\left(\kappa_{\ell}+\kappa_{f}\right) \phi(j)\right) h,
$$

where $r(j)=1300 \eta e_{9}$ denotes the release rate on day $j$ and $\phi(j)$ denotes a Bernoulli variable which takes the value 1 if sterile moths are released on day $j$, or 0 otherwise. Furthermore, $h$ denotes the area (in hectares) of the release $\operatorname{site}^{3}$.

\footnotetext{
${ }^{2}$ Aircraft fly along predetermined equally spaced release paths across the domain. Achieving a uniform distribution depends significantly on the dispersal capability of the insect and the corresponding choice of release paths. Release flight paths in SIT programmes usually range between 100 and 500 metres apart, but depend on the species' capability to disperse [41].

${ }^{3}$ A one-hectare field contains, on average, 130000 stalks in South Africa. An infestation of 1 e/100s is
} 


\subsection{The crop damage index}

Varietal screening trials conducted at SASRI have revealed that the length of stalk bored per larvae is independent of the variety grown [24]. The total average length of stalk bored per larvae assumed in this study is $42.525 \mathrm{~mm}$ [36]. The daily feeding rate is approximated by the reciprocal of the average development time spent $\left(\alpha_{L_{2}}(t, \tau)\right)$ in each stage multiplied by 42.525. The damage index $\delta(t)$ on any day $t$ is defined as the cumulative total of larvae feeding up to day $t$ in a given field since the crop was planted, measured as a percentage of the total of stalk length on day $t$, and is given by

$$
\delta(t)=\frac{\sum_{j=0}^{t} \sigma(j)\left(\mathcal{E}_{5}(j)+\mathcal{E}_{6}(j)\right)}{\ell(t)},
$$

where $\sigma(j)$ denotes the amount of larval feeding per larvae on day $j$ and where $\ell(t)$ denotes the average stalk length on day $t$, estimated by

$$
\ell(t+1)=\ell(t)+0.16(24)(-1.77+0.176(\tau-10)+0.45)
$$

for a two-year cycle crop, according to the CANEGRO model [6].

\subsection{Increase in revenue as a result of the SIT}

The South African Sugar Industry has, since the start of the 2000/01 season, adopted the Recoverable Value (RV) payment system [8]. In order to calculate the payment due to a farmer, the RV percentage is multiplied by the number of tons of sugarcane delivered and the RV price [7]. The RV formula is $R V=S-d N-c F$, where $S$ denotes the percentage of sucrose in cane delivered, $d$ denotes the relative value of sucrose lost from sugar production per unit of non-sucrose (taking into account the value of molasses recovered per unit of nonsucrose) and $N$ denotes the percentage of non-sucrose in the cane delivered. Furthermore, $c$ denotes the loss of sucrose from sugar production per unit of fibre and $F$ denotes the percentage of fibre in the cane delivered [8]. The values for $c$ and $d$ assumed in this study are 0.0198 and 0.5506 , respectively [24]. The values for $N$ and $F$ are taken as the industry averages for 2010, which are 2.61 and 14.6, respectively [30]. The percentage sucrose $S$ of mature sugarcane on day $t$ is given by

$$
S=100 \frac{-1.31 \delta(t)+84}{-5.78 \delta(t)+556},
$$

where the numerator denotes the sucrose mass in $g / s t a l k$, while the denominator denotes the stalk mass in $g / s t a l k$, and where $\delta(t)$ denotes the percentage internodes bored in mature sugarcane on day $t$. The sucrose mass and stalk mass of the cane were obtained from data of a previous study conducted on sugarcane growth and yield at Gingindlovu, KwaZulu-Natal [20]. The relationship between the percentage sucrose $S$ and the percentage internodes bored $\delta(t)$ is illustrated graphically in Figure 4.

For the purposes of this study, the RV price per ton of the 2011/2012 milling season is adopted, which was recorded at $\mathrm{R} 2817.05$. The revenue is therefore given by

$$
W=2817.05 T \frac{R V}{100},
$$

therefore equivalent to 1300 larvae per ha. 


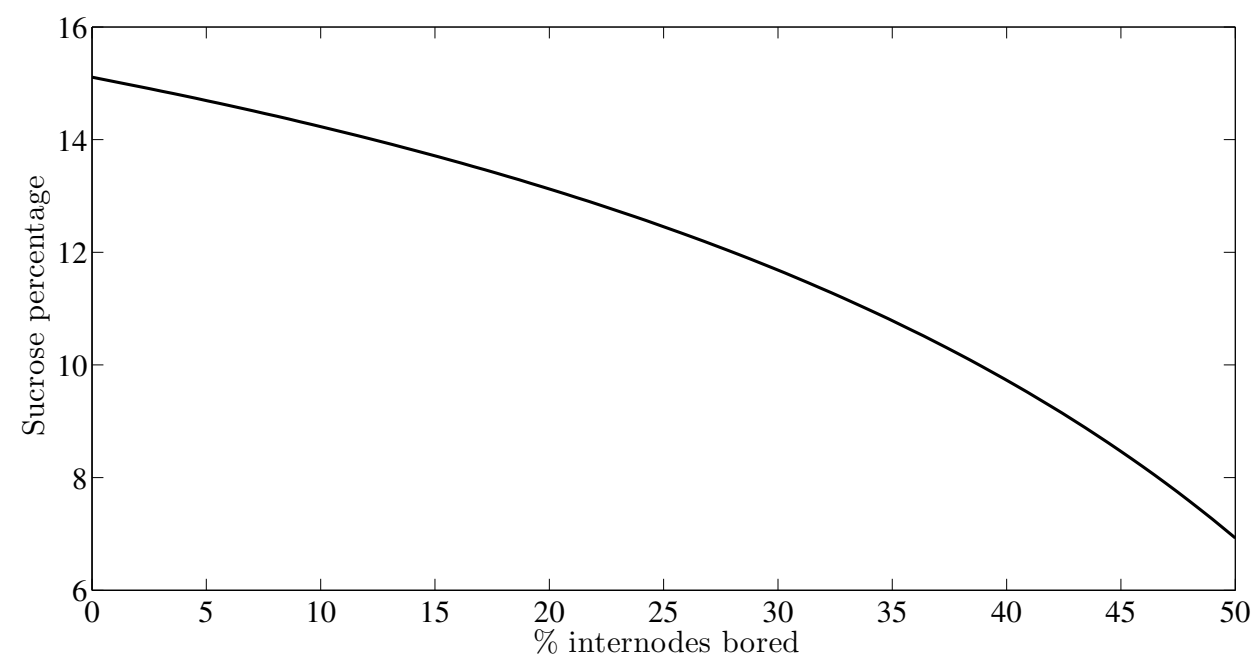

Figure 4: The relationship between sucrose percentage in cane delivered and the percentage of internodes bored [20].

where $T$ denotes the average number of tons of sugarcane delivered. The relationship between the revenue per hectare $W$ and the percentage internodes bored $\delta(t)$ is illustrated graphically in Figure 5.

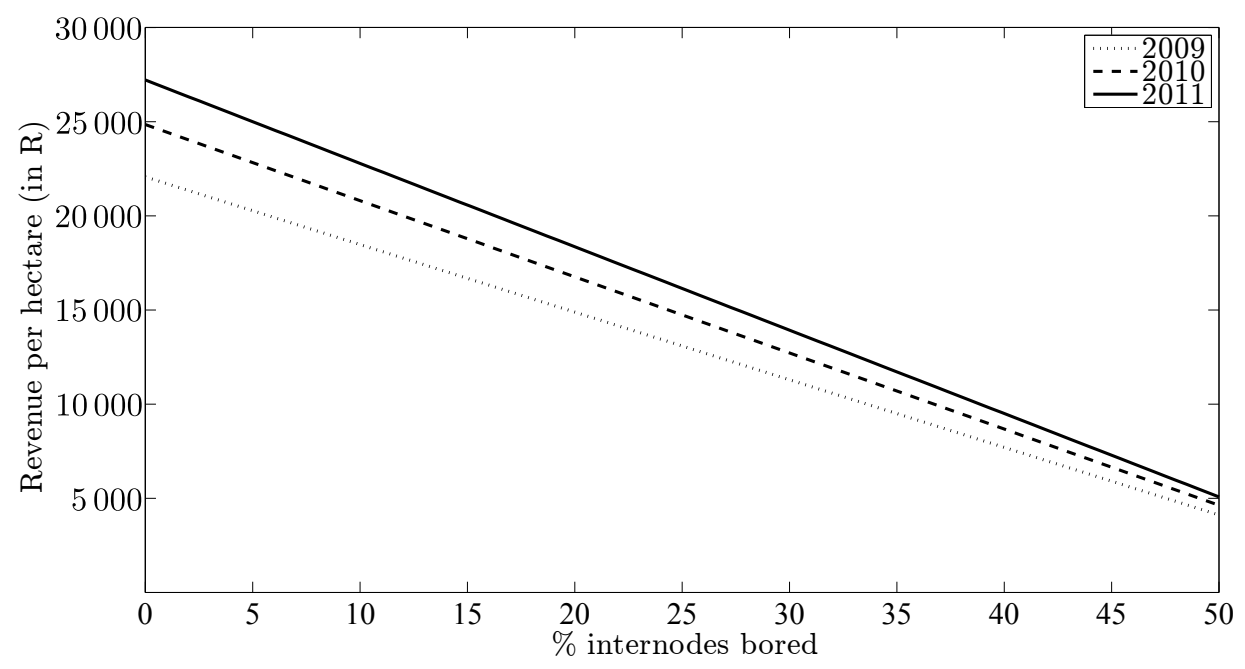

Figure 5: The relationship between the revenue per hectare for cane delivered and the percentage of internodes bored assuming the 2009, 2010 and 2011 RV prices of R2284.20, R2572.14 and $R 2817.05$, respectively.

The increase in revenue as a result of the SIT is given by $I=W_{S I T}-W$, where $W_{S I T}$ denotes the revenue if a certain SIT strategy is applied. The profit made as a result of the SIT is given by $P=I-C$. 


\section{Model validation}

Any mathematical model must necessarily make simplifying assumptions in order to describe a part of a real-world process. In order to determine whether the model described in $\S 2$ provides a satisfactory representation of E.saccharina infestation in sugarcane in South Africa, the model was tested against data sets obtained from the Sezela mill in KwaZulu-Natal [30], where infestation is considered fairly low.

All simulations reported in this paper were performed for a field size of 1 ha over a time period of 24 months, with initial population levels chosen as $0.1 \mathrm{e} / 100 \mathrm{~s}$ together with appropriate initial values for larvae, pupae and moth populations. The fertile proportion of the $F_{1}$ generation of released sterile males was taken as 0.1 , the residual fertility in released moths was taken as 0 , the male and female competitivity were taken as 1 and 0.1 , respectively, sperm competitivity was taken as 1 , and sterile releases included males and females.

Data obtained from the Sezela mill for 2010 indicate an average of $3.78 \mathrm{e} / 100 \mathrm{~s}$ at an average cane age of 13.6 months. The average percentage stalks red ${ }^{4}$ was measured at $2.08 \%$ [30], which is equivalent to the average percentage of internodes damaged [20]. The model without sterile releases, when assuming the density-dependent mortality function $b(t)=$ $\frac{10}{\left(d^{2.5}+1\right)}$, gives an E.saccharina infestation of $4 \mathrm{e} / 100 \mathrm{~s}$ at 13.6 months, which corresponds to the Sezela data, and then increases to 18.39 e/100s at the end of a 24-month cycle. The percentage internodes damaged according to the model, however, underestimates the internode damage due to E.saccharina. At 13.6 months the percentage internodes damaged are given as $0.85 \%$. A possible reason why the model may underestimate the percentage damage, is due to the fact that the model assumes ideal growth conditions for cane. During 2010 the area around the Sezela mill experienced low rainfall. Stalks under stressed conditions (low rainfall) achive a lower height than in ideal conditions, and are much more vulnerable to E.saccharina infestation. A stalk height of $0.7 \mathrm{~m}$ at maturation is not uncommon in stressed cane. The model without sterile releases, when assuming the density-dependent mortality function $b(t)=\frac{7}{\left(d^{2.5}+1\right)}$ and an estimation of the average stalk length on day $t$ in stressed cane given by $\ell(t+1)=\ell(t)+0.16(24)(-1.77+0.15(\tau-$ $10)+0.45)$, yields an average E.saccharina infestation of $5.7 \mathrm{e} / 100 \mathrm{~s}$ at 13.6 months, and a percentage internodes damaged of $2.3 \%$, which corresponds more closely to the 2010 Sezela mill data.

Another reason why the model may underestimate the percentage damage is that the mill data may have been obtained when larval levels were at a seasonal low. Infestation levels earlier in the season may have been much higher under the stressed conditions. The model output was also compared to infestation and damage data obtained during 1998 from a biological control research project performed in the Melmoth area in KwaZulu-Natal, including infestation levels during winter and summer months of the last few months of growth for certain fields. The model results without sterile releases, when assuming the density-dependent mortality function $b(t)=\frac{1.2}{\left(d^{1.1}+1\right)}$, compared well to infestation and damage data from the biological control site (see Figure 6). In order to test whether

\footnotetext{
${ }^{4}$ Stalk damage due to E.saccharina results in certain portions of the stalk around the borings turning red.
} 

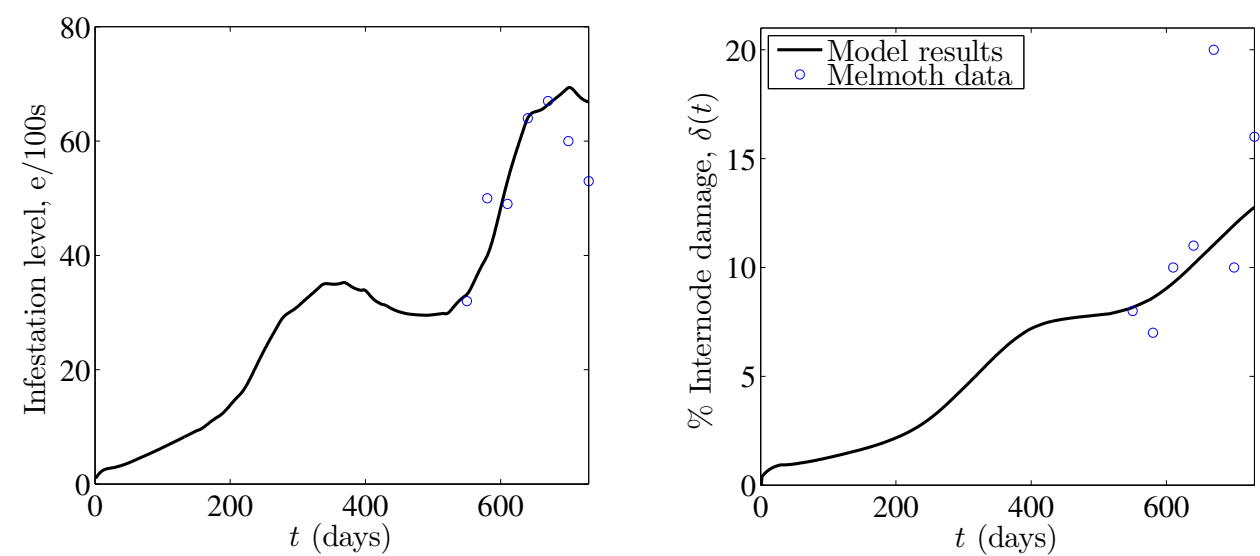

Figure 6: Comparison of infestation and damage data obtained from the Melmoth area with simulation results.

the model underestimates damage or whether infestation levels may have been higher, infestation and corresponding damage data for every month of the crop cycle are required. Unfortunately, no such data were available during the time of this study.

If sterile moths were released, starting in the beginning of the sugarcane cycle in a scenario similar to the Sezela mill recorded infestation levels with $b(t)=\frac{7}{\left(d^{2.5}+1\right)}$, the minimum daily release ratio of sterile moths required to suppress E.saccharina exponential growth is $0.06685: 1$. This ratio seemed to be too low compared to release ratios of other SIT projects $[1,23]$. However, the ratio of $0.06685: 1$ is a daily release ratio whereas most of the recorded release ratios are per generation. In order to estimate a release ratio which is more comparable to those in existing SIT projects, weekly rather than daily releases were also simulated. The model calculates the change in the number of released sterile moths per day via the expression

$$
f_{11}(t, \underline{\mathcal{E}})=r(t)-\mu_{S}(t, \tau) \mathcal{E}_{11}(t),
$$

where $r(t)$ and $\mu_{S}(t, \tau)$ denote the daily release rates and mortality rates, respectively. If, however, releases are once per week with the release rate equal to zero on any other day, the mortality rate needs to be adjusted accordingly. The number of moths which die on a specific day should be calculated as a fraction of the number of moths present on the previous release day rather than as a fraction of the moths present on the previous day. If the change in the number of released sterile moths per day is given by

$$
f_{11}(t, \underline{\mathcal{E}})=r(t)-\mu_{S}(t, \tau) \mathcal{E}_{11}\left(t_{r}\right),
$$

where $\mathcal{E}_{11}\left(t_{r}\right)$ denotes the released moth population on the previous release day, the release ratio necessary to suppress an E.saccharina infestation is estimated at $0.775: 1$. This weekly release ratio also seemed to be too low compared to those employed in current SIT projects.

The model described in $\S 2$ assumes an even distribution of E.saccharina released and native populations across the entire domain during each time step. The underlying assumption is that all areas within the habitat are equally connected and that individual organisms 
encounter one another in proportion to their average abundance across space (mean-field assumption) [18]. This may be a rather unrealistic assumption if releases result in an uneven distribution of released sterile moths, as in the case of aerial releases where the flight paths are too far apart - E.saccharina is a relatively weak flier and released sterile moths may take a few time steps to disperse across the domain. Also, if the environment is heterogeneous in terms of cane age and variety, where different E.saccharina subpopulations do not experience the same mortality rates, the population growth and distribution of E.saccharina cannot be described by the mean-field approximation and needs to be modelled as a function of both time and space. In order to present a more realistic model for unevenly distributed releases, or for a heterogeneous environment, a spatial dimension needs to be included in the mean-field model described in this paper.

\section{Model Analysis}

As mentioned in $§ 2.1$, the optimal release ratio which maximises profit for each release frequency was obtained by means of simulation runs of the model described in $\S 2$. The optimal release strategy $(\eta, \theta)_{\text {opt }}$ was obtained by comparing the profit obtained at the optimal release ratios for the different release frequencies. For illustrative purposes, the cost per sterile insect (excluding labour and fuel costs) was assumed to be R0.10, and the UAV cost per application (labour and fuel) was assumed to be R5.80/ha. Growing conditions were assumed to be ideal; therefore the average stalk length on day $t$ is given by (9). Also, the density-dependent mortality function $b(t)=\frac{4}{\left(d^{2.5}+1\right)}$ was assumed. Simulations were performed for both a resistant $(\omega=5)$ and susceptible variety $(\omega=8)$ of cane. Infestation and damage profiles for both varieties are shown in Figure 7. After 24 months, the resistant variety is expected to yield a revenue of R24 914.92/ha (comprising a loss in revenue of R2 332.55/ha due to E.saccharina infestation) with $\delta=5.2629$, whereas the more susceptible variety is expected to yield a revenue of R19 964.16/ha (comprising a loss in revenue of $\mathrm{R} 7283.31 /$ ha) with $\delta=16.4332$.
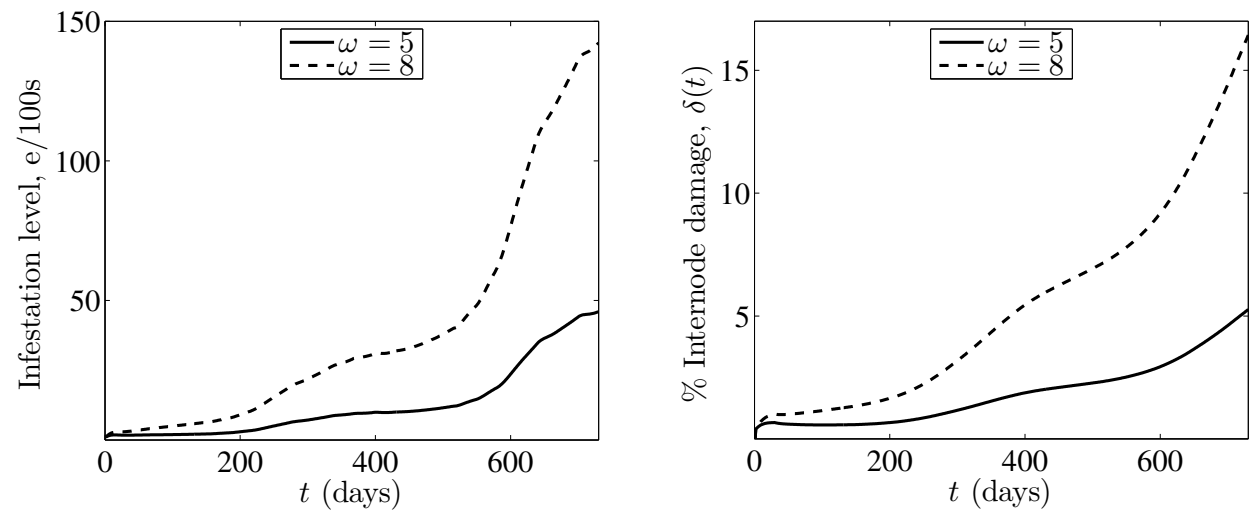

Figure 7: Model simulation results of E.saccharina larval infestation (measured in e/100s) and corresponding percentage internode damage $\delta(t)$ for $\omega=5$ and $\omega=8$.

For cane with a similar infestation profile than the resistant and susceptible variety used in the simulations, the maximum increase in revenue due to the SIT was estimated at 
R2 332.55/ha and R7283.31/ha, respectively, and, for any economically viable strategy, this should also be the maximum cost allowed per hectare. Although releases performed on a daily basis required much smaller release ratios in order to achieve suppression (and therefore much lower risk involved in not achieving suppression), the application cost for daily releases exceeded the expected increase in revenue by far. The less frequent releases are, the higher the risk becomes of not achieving suppression. The lifespan of an Eldana moth is approximately one week; released sterile moths therefore have more or less a week in which they have an impact on the native population. Releases performed weekly were more cost-effective compared to releases performed twice a week. The optimal aerial release strategy (for the assumed parameter values and initial infestation level) where the SIT profit $P$ is maximised, was estimated at $(1.422,7)$ and $(4.287,7)$ for the resistant and susceptible variety, respectively (see Figures 8 and 9 ). If releases were performed less frequently than once a week, suppression of E.saccharina below 5 e/100s became difficult, requiring much larger release ratios. Suppression below 5 e/100s was not possible for releases performed once every two weeks in the susceptible variety, even at high release ratios of $200: 1$. For releases once every three weeks, even at a release ratio of $1000: 1$, suppression below $10 \mathrm{e} / 100 \mathrm{~s}$ was not possible. Due to the risk of higher infestation levels, it is therefore not considered a viable option to release less frequently than once a week.
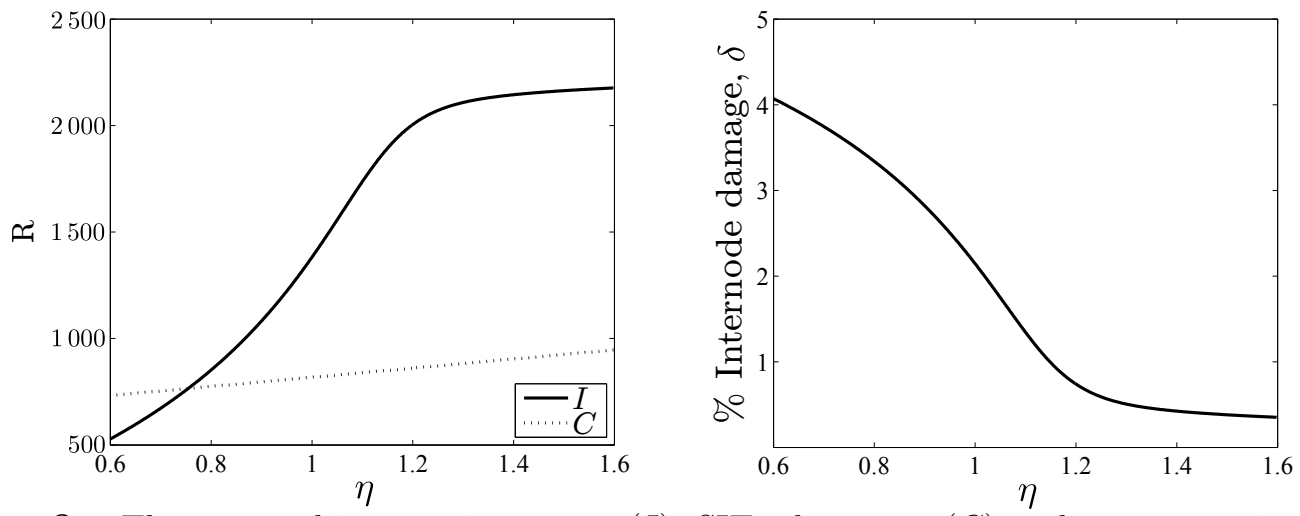

Figure 8: The expected increase in revenue $(I), S I T$ release cost $(C)$ and percentage internode damage for $\omega=5$ and with the release strategy varied from $(0.6,7)$ to $(1.6,7)$.
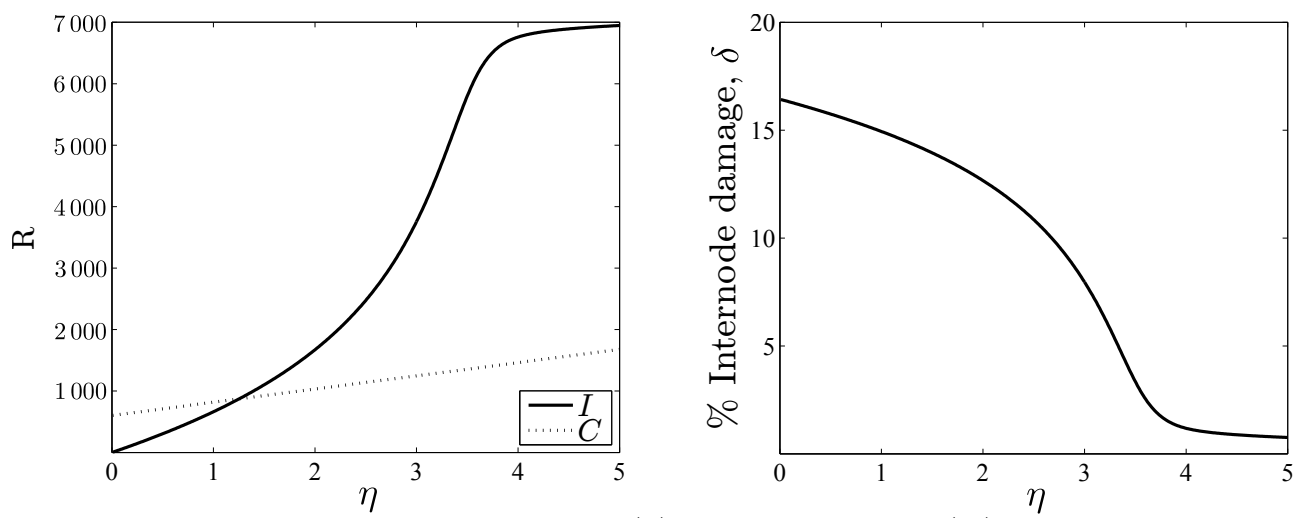

Figure 9: The expected increase in revenue $(I)$, SIT release cost $(C)$ and percentage internode damage for $\omega=8$ and with the release strategy varied from $(0.01,7)$ to $(5,7)$. 
The application cost of aerial releases may be higher than R5.80 per hectare; however, this would not change the optimal release ratio. This is easily verifiable in Figures 10 and 11, where, if the application cost increases, the graph representing $C$ merely shifts upwards with no change in the gradient of the graph, therefore having no effect on the optimal release ratios. If $\kappa_{r} \neq 0.1$, then the optimal release ratio may change due to a change in the gradient of the graph representing $C$. The values of $C$ represented in Figures 10 and 11 at different release ratios (assuming an initial infestation of $0.1 \mathrm{e} / 100 \mathrm{~s}$ ) were obtained under the assumption that releases were performed twice a week or weekly over a period of two years.

As mentioned in $\S 3$, it is possible that the model underestimates $\delta$, in which case the maximum increase in revenue may be larger than $\mathrm{R} 2332.55 /$ ha and $\mathrm{R} 7283.31$ /ha, respectively. If the model underestimates $\delta$, the optimal release ratio may change. On the other hand, infestation levels will remain the same at different release ratios, and hence the minimum release ratio required for suppression below 5 e/100s remains the same.

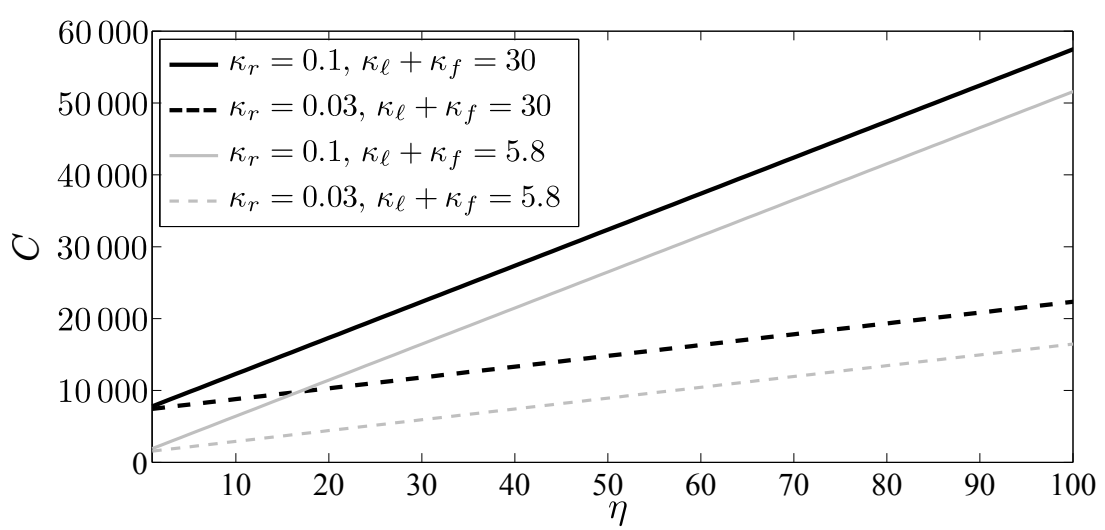

Figure 10: Comparison between estimated values of $C$ at different release ratios with aerial releases performed twice a week on a 1 hectare field over a period of 24 months.

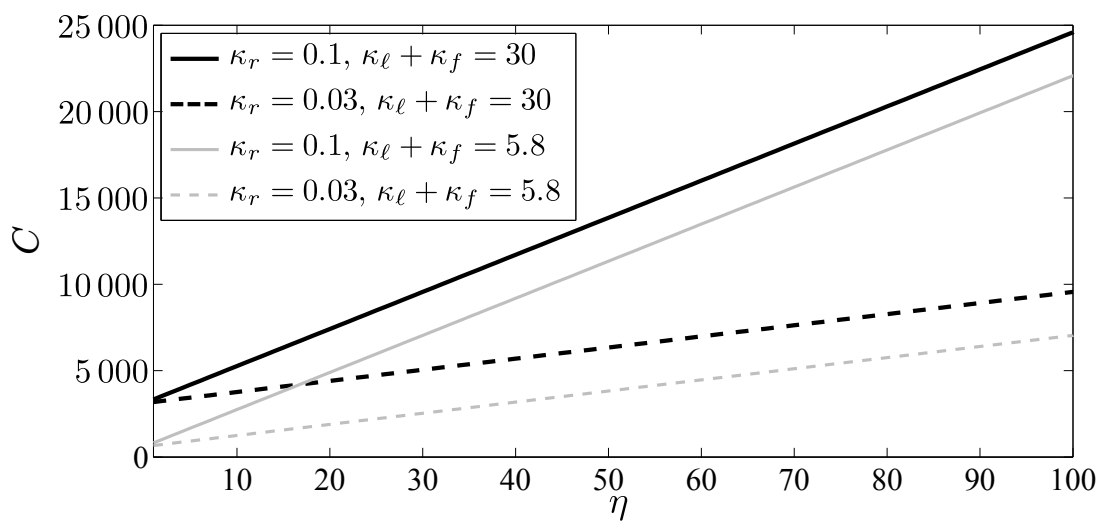

Figure 11: Comparison between estimated values of $C$ at different release ratios with aerial releases performed weekly on a 1 hectare field over a period of 24 months. 


\section{Sensitivity Analysis}

The model described in $\S 2.1$ assumes certain parameter values obtained from laboratory experiments which may be different from data in actual field behaviour. For some of the parameter values, no experimental values were available at the time of writing, and certain values had to be assumed. In order to test whether the model output is reliable, single input parameters were perturbed while keeping all other parameters constant. For the purposes of decision aid, this basic sensitivity analytic approach is considered adequate [34]. A more formal and explicit use of probabilities in sensitivity analysis was therefore excluded from the results presented in this section. This is also due to a lack of knowledge about the probability distribution of most of the parameter values.

The average elasticities ${ }^{5}$ of $\eta_{\text {opt }}, \max (P)$ and $\delta$ with respect to changes in the various parameters are given in Table 5 .

The optimal release ratio is the most sensitive to changes in $\lambda_{f}, \mu_{L_{1}}, \mu_{L_{2}}, \alpha_{L_{1}}, \alpha_{L_{2}}, c_{m}$, $m$ and $y$. The optimal release ratio does not appear to be very sensitive to changes in the initial infestation level (see Table 6) or the maximum number of matings per moth (see Table 7). In the case that the model underestimates damage levels, $\eta_{\text {opt }}$ is not too sensitive to changes in damage levels (the elasticity of $\eta_{o p t}$ with respect to changes in $\sigma$ is $0.134)$.

\begin{tabular}{crrrr}
\hline Parameter & $\begin{array}{l}\text { Elasticity } \\
\text { of } \eta_{\text {opt }}\end{array}$ & $\begin{array}{l}\text { Elasticity } \\
\text { of } \max (P)\end{array}$ & $\begin{array}{l}\text { Elasticity of } \delta \\
\text { when } \eta=1.422\end{array}$ & $\begin{array}{l}\text { Elasticity of } \delta \\
\text { when } \eta=1.8\end{array}$ \\
\hline$\lambda_{f}$ & 1.793 & -0.584 & 13.245 & 3.106 \\
$\mu_{L_{1}}$ & -1.169 & 0.406 & -6.031 & -2.018 \\
$\alpha_{L_{2}}$ & 1.041 & -0.697 & 5.353 & 2.251 \\
$\alpha_{L_{1}}$ & 1.021 & -0.342 & 3.460 & 1.514 \\
$\mu_{L_{2}}$ & -0.972 & 0.348 & -4.089 & -1.715 \\
$c_{m}$ & -0.882 & 0.245 & -4.524 & 1.155 \\
$m$ & -0.850 & 0.233 & -4.319 & -1.044 \\
$y$ & -0.767 & 0.279 & -2.659 & -1.353 \\
$c_{s}$ & -0.471 & 0.130 & -1.145 & -0.495 \\
$\lambda_{s}$ & -0.339 & 0.061 & -0.481 & -0.101 \\
$\mu_{E}$ & -0.239 & 0.082 & -0.571 & -0.376 \\
$\kappa_{r}$ & -0.141 & -0.246 & 0.000 & 0.000 \\
$\alpha_{E}$ & 0.141 & -0.038 & 0.253 & 0.121 \\
$\sigma$ & 0.134 & -0.148 & 1.000 & 1.000 \\
$\mu_{P}$ & -0.098 & 0.049 & -0.233 & -0.148 \\
$\beta$ & 0.085 & -0.022 & 0.152 & 0.078 \\
$\mu_{M}$ & -0.044 & 0.330 & -0.521 & -0.281 \\
$z$ & -0.042 & 0.025 & -0.168 & -0.143 \\
$c_{f}$ & -0.025 & 0.011 & -0.076 & -0.070 \\
$\alpha_{P}$ & 0.002 & -0.007 & -0.049 & -0.086 \\
$\kappa_{\ell}+\kappa_{f}$ & 0.000 & -0.489 & 0.000 & 0.000 \\
\hline
\end{tabular}

Table 5: Average elasticities of $\eta_{\text {opt }}, \max (P)$ and $\delta$.

The maximum SIT profit (the profit obtained at the optimal release ratio) is the most

\footnotetext{
${ }^{5}$ The elasticity of a dependent variable is a measure of the percentage change in the variable for every one percentage point change in an independent variable (parameter).
} 
sensitive to changes in $\alpha_{L_{2}}, \lambda_{f}, \kappa_{\ell}, \kappa_{f}, \mu_{L_{1}}, \alpha_{L_{1}}, \mu_{L_{2}}, \mu_{M}, c_{m}, m, y$ and $\kappa_{r}$. The maximum SIT profit is very sensitive to changes in the initial infestation level (see Table 6) — for a specific release ratio, the number of moths released is larger for higher initial infestation levels, thereby increasing the release cost and decreasing the SIT profit. In order to maximise the SIT profit, care should therefore be taken to apply the SIT when initial infestation levels are at a seasonal low, or to apply the SIT in combination with other control measures. The maximum SIT profit is rather insensitive to changes in the maximum number of matings per moth (see Table 7). In the case that the model underestimates damage levels, $\max (P)$ is not too sensitive to changes in damage levels (the elasticity of $\max (P)$ with respect to changes in $\sigma$ is -0.148$)$.

\begin{tabular}{cccccc}
\hline Initial infestation & $\eta_{\text {opt }}$ & $\max (P)$ & $\delta$ & Profit range of $\eta$ & Profit when $\eta=1.8$ \\
\hline $0.1 \mathrm{e} / 100 \mathrm{~s}$ & 1.422 & $\mathrm{R} 1241.19$ & 0.4125 & {$[0.755 ; 7.745]$} & $\mathrm{R} 1205.08$ \\
$0.2 \mathrm{e} / 100 \mathrm{~s}$ & 1.326 & $\mathrm{R} 948.45$ & 0.4125 & {$[0.855 ; 3.383]$} & $\mathrm{R} 818.61$ \\
$0.3 \mathrm{e} / 100 \mathrm{~s}$ & 1.286 & $\mathrm{R} 668.41$ & 0.4125 & {$[0.943 ; 2.522]$} & $\mathrm{R} 432.14$ \\
$0.4 \mathrm{e} / 100 \mathrm{~s}$ & 1.262 & $\mathrm{R} 394.99$ & 0.4125 & {$[1.03 ; 1.857]$} & $\mathrm{R} 45.67$ \\
\hline
\end{tabular}

Table 6: Changes in $\eta_{\text {opt }}, \max (P)$ and $\delta$ for various initial infestation levels. The range of $\eta$ for which an SIT profit is obtained is also given, together with the profit estimated when $\eta=1.8$.

\begin{tabular}{cccc}
\hline$B$ & $\eta_{\text {opt }}$ & $\max (P)$ & $\delta$ \\
\hline 1 & 1.164 & $\mathrm{R} 1319.44$ & 0.3610 \\
2 & 1.290 & $\mathrm{R} 1282.00$ & 0.3844 \\
3 & 1.356 & $\mathrm{R} 1261.77$ & 0.3981 \\
4 & 1.390 & $\mathrm{R} 1251.39$ & 0.4050 \\
5 & 1.414 & $\mathrm{R} 1243.36$ & 0.4115 \\
6 & 1.422 & $\mathrm{R} 1241.19$ & 0.4125 \\
\hline
\end{tabular}

Table 7: Changes in $\eta_{\text {opt }}, \max (P)$ and $\delta$ for various numbers of matings per male, $B$.

The sensitivity of $\delta$ was tested by perturbing the various parameters by a certain percentage (but keeping the release ratio constant at 1.422), and then finding $\delta$ for the new set of parameter values. From Figure 12, $\delta$ appears to be the most sensitive to changes in $\lambda_{f}$, $\mu_{L_{1}}, \mu_{L_{2}}, \alpha_{L_{1}}, \alpha_{L_{2}}$ (which correspond to the sensitivity analysis of the model proposed by Horton [24]), $c_{m}, m, y, c_{s}$ and $\sigma$. Also, $\delta$ is much more sensitive when decreasing the values of $c_{m}, c_{s}, m, \mu_{L_{1}}, \mu_{L_{2}}$ and $y$ than when these parameter values are increased, and when $\alpha_{L_{1}}, \alpha_{L_{2}}$ and $\lambda_{f}$ are increased than when these parameter values are decreased. From Table 5 it may be seen that $\delta$ around $\eta_{o p t}$ is the most sensitive output parameter compared to the elasticities of $\eta_{\text {opt }}$ and $\max (P)$. The elasticities of $\delta$ when $\eta=1.422$ compared to when $\eta=1.8$ indicates that $\delta$ becomes less sensitive to all parameters when $\eta>\eta_{\text {opt }}$. If the objective is to maximise profit together with minimising risk $^{6}$ rather than only maximising profit, it may therefore be better to choose a larger value for $\eta$ within the profit range than to choose $\eta_{\text {opt }}$ where $\max (P)$ is obtained and where $\delta$ is extremely sensitive to changes in some of the parameters (see Table 6).

Since all of the output parameters $\left(\eta_{\text {opt }}, \max (P)\right.$ and $\left.\delta\right)$ are relatively insensitive to changes

\footnotetext{
${ }^{6}$ In the context of this study risk may be interpreted as higher infestation and damage levels than expected.
} 

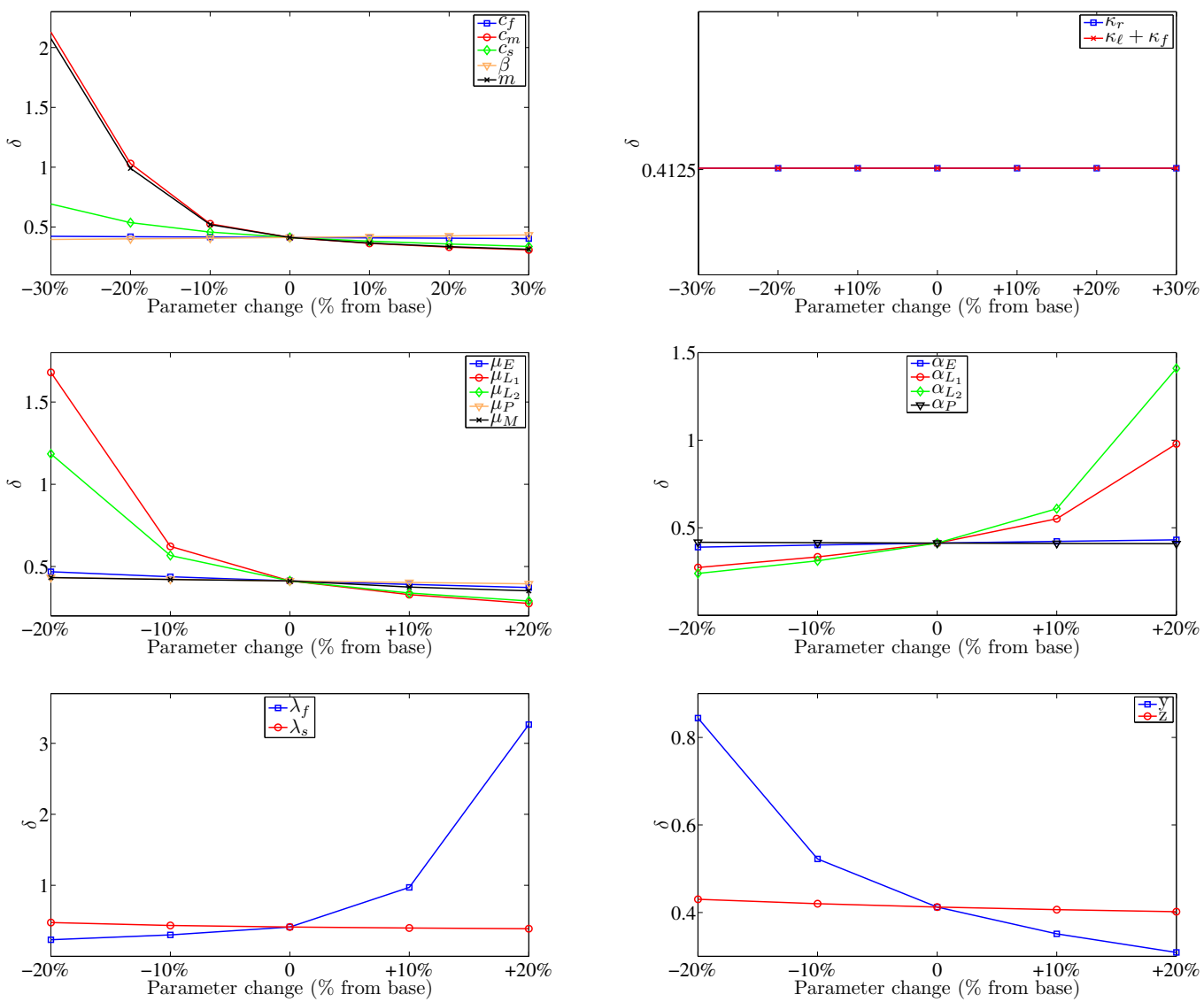

Figure 12: The sensitivity of the percentage damage $\delta$ with respect to percentage changes in various parameters when the release ratio is kept constant at $\eta_{\text {opt }}$.

in $c_{f}$ and sensitive to changes in $c_{m}$ and $m$, released sterile males may have a much more significant impact on infestation and damage levels than released sterile females. This corresponds with the large-scale field comparison between males-only and bisexual sterile fly releases in Guatemala [38]. Releasing only sterile males instead of both males and females is therefore considered a better (and effective) strategy. The optimal release ratio, maximum SIT profit and $\delta$ were also estimated for releases starting at different crop ages. The profit was more than R1000 if releases commenced between 0 and 5 months, with $\delta<1$. Releases commenced at a crop age of more than 5 months resulted in increased damage levels, with the profit decreasing at a higher rate for each month older at which releases commenced (see Figure 13). It is therefore not recommended to commence releases at a crop age older than 5 months.

\section{Recommendations}

Suppression is obtained at smaller release ratios when releases are performed twice a week compared to weekly releases. The risk of not obtaining suppression is therefore lower compared to weekly releases. However, weekly releases are more cost-effective compared 

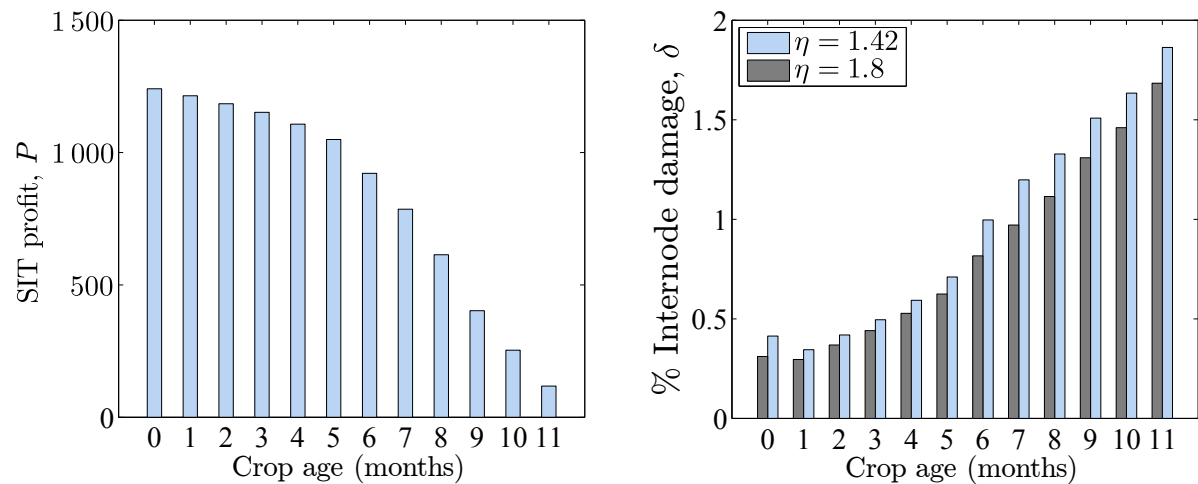

Figure 13: SIT profit and damage levels for releases commenced at different crop ages.

to releases performed twice a week. It is not recommended to commence releases at a crop age older than 5 months, since commencing at older crop ages may result in increased damage levels and therefore decreased profit levels. The SIT profit may also be maximised by applying the SIT when initial infestation levels are at a seasonal low, or by applying the SIT in combination with other control measures. It is also recommended that only sterile males should be released - sterile males have a much more significant impact on infestation and damage levels than do sterile females.

\section{Conclusion}

A detailed description was presented of a novel model for E.saccharina population growth and interaction with sterile released moths. A description of the parameters incorporated into the model was also given together with the derivation of the fertilization probabilities $\gamma$ and $\rho$. In contrast with previous SIT models, which consider only the male mating probabilities, the fertilization probabilities include both the probability of mating with a certain type of male (fertile or sterile) and mating with a certain type of female. The optimal release strategy for an assumed parameter set was obtained by means of repeated simulation runs of the model. Finally, a sensitivity analysis was performed in order to ascertain the robustness of the optimal strategy (in terms of profit) with respect to different parameter values.

\section{References}

[1] Addison MF, 2004, Suppression of codling moth Cydia pomonella L. (Lepidoptera: Tortricidae) populations in South African apple and pear orchards using sterile insect release, Proceedings of the IXth International Pear Symposium, South Africa, pp. 555-557.

[2] AtKinson PR, 1979, Distribution and natural hosts of Eldana saccharina Walker in Natal, its oviposition sites and feeding patterns, Proceedings of the South African Sugar Technologists Association, 53, pp. 111-115.

[3] AtKinson PR, 1980, On the biology, distribution and natural host-plants of Eldana saccharina Walker, Journal of the Entomological Society of South Africa, 43, pp. 171-194. 
[4] Atkinson PR \& Carnegie AJM, 1989, Population dynamics of the sugarcane borer, Eldana saccharina Walker, in Natal, South Africa, Bulletin of Entomological Research, 79, pp. 61-80.

[5] BerRyman A, 1967, Mathematical description of the sterile male principle, The Canadian Entomologist, 99, pp. 858-865.

[6] Bezuidenhout CN, 2000, A model review and proposed mechanistic tiller model for the Canegro sugarcane crop model, MSc Thesis, Technikon Natal, Durban.

[7] Bezuidenhout CN, 2011, Associate Professor at the University of KwaZulu-Natal (Pietermaritzburg Campus), [Personal Communication], Contactable: bezuidenhoutc@ukzn.ac.za.

[8] Canegrowers, 2002, The RV cane payment system, [Online], [Cited: 23 May 2011], Available: http://www.sacanegrowers.co.za/facts-figures/rv-cane-payment-system/.

[9] Carnegie AJM, 1974, A recrudescence of the borer Eldana saccharina Walker (Lepidoptera: Pyralididae), Proceedings of the South African Sugar Technologists Association, 48, pp. 107-110.

[10] Carnegie AJM, 1981, Combating Eldana saccharina Walker: A progress report, Proceedings of the South African Sugar Technologists Association, 55, pp. 116-119.

[11] Carnegie AJM \& Smaill RJ, 1980, The incidence of moth borers in South African sugarcane during the 1979/80 season, Proceedings of the South African Sugar Technologists Association, 54, pp. $154-157$.

[12] Carnegie AJM \& Smaill RJ, 1982, Pre-trashing of sugarcane as a means of combating the borer Eldana saccharina Walker, Proceedings of the South African Sugar Technologists Association, 56, pp. $78-81$.

[13] Conlong DE, 1990, A study of pest-parasitoid relationships in natural habitats: An aid towards the biological control of Eldana saccharina (Lepidoptera: Pyralidae) in sugarcane, Proceedings of the South African Sugar Technologists Association, 64, pp. 111-115.

[14] Conlong DE, 1994, A review and perspectives for the biological control of the African sugarcane stalkborer Eldana saccharina Walker (Lepidoptera: Pyralidae), Agriculture, Ecosystems and Environment, 48, pp. 9-17.

[15] Conlong DE, 1997, Biological control of Eldana saccharina Walker in South African sugarcane: Constraints identified from 15 years of research, Insect Science and its Application, 17(1), pp. 6978.

[16] Conlong DE, 2001, Biological control of indigenous African stemborers: What do we know?, Insect Science and its Application, 21(4), pp. 267-274.

[17] Conlong DE \& Rutherford RS, 2009, Conventional and new biological and habitat interventions for Integrated Pest Management systems: Review and case studies using Eldana saccharina Walker (Lepidoptera: Pyralidae), pp. 241-261 in PESHIN R \& DHAWAN AK (Eds), Integrated pest management: Innovation-development process, Springer, New York (NY).

[18] Dieckmann U, LAW R \& Metz JAJ, 2000, The geometry of ecological interactions: Simplifying spatial complexity, Cambridge University Press, Cambridge.

[19] Dyck VA, Hendrichs J \& Robinson AS, 2005, Sterile insect technique — Principles and practice in area-wide integrated pest management, Springer, Dordrecht.

[20] Goebel FR \& WAY MJ, 2003, Investigation of the impact of Eldana Saccharina (Lepidoptera: Pyralidae) on sugarcane yield in field trials in Zululand, Proceedings of the South African Sugar Technologists Association, 77, pp. 256-265.

[21] Hearne JW, van Coller LM \& Conlong DE, 1991, Determining strategies for the biological control of a sugarcane stalk borer, Ecological Modelling, 73, pp. 117-133. 
[22] Heathcote RJ, 1984, Insecticide testing against Eldana saccharina Walker, Proceedings of the South African Sugar Technologists Association, 58, pp. 154-158.

[23] Hofmeyr JH, Carpenter JE \& Bloem S, 2005, Developing the Sterile Insect Technique for Cryptophlebia leucotreta (Lepidoptera: Tortricidae): Influence of radiation dose and release ratio on fruit damage and population growth in field cages, Journal of Economical Entomology, 98(6), pp. 19241929.

[24] Horton PM, 2008, A simulation modelling approach to aid research into the control of a stalk-borer in the South African sugar industry, PhD Dissertation, University of KwaZulu-Natal, Pietermaritzburg.

[25] Horton PM, Hearne JW, Apaloo J, Conlong D, Way MJ \& Uys PW, 2002, Investigating strategies for minimising damage caused by the sugarcane pest Eldana saccharina, Agricultural Systems, 74, pp. 271-286.

[26] Keeping MG \& Rutherford RS, 2004, Resistance mechanisms of South African sugarcane to the stalk borer Eldana saccharina (Lepidoptera: Pyralidae): A review, Proceedings of the South African Sugar Technologists Association, 78, pp. 307-312.

[27] KIng AG, 1989, An assessment of the loss in sucrose yield caused by the stalk borer, Eldana Saccharina, in Swaziland, Proceedings of the South African Sugar Technologists Association, 63, pp. 197201.

[28] Kvedaras OL, Keeping MG, Goebel R \& Byrne M, 2005, Effects of silicon on the African stalk borer, Eldana saccharina (Lepidoptera: Pyralidae) in sugarcane, Proceedings of the South African Sugar Technologists Association, 79, pp. 359-363.

[29] LESLIE GW, 1990, Influence of dead leaf material on oviposition behaviour of Eldana saccharina (Lepidoptera: Pyralidae) in sugarcane, Proceedings of the South African Sugar Technologists Association, 64, pp. 100-102.

[30] Mcelligott D, 2010, Hibberdene/Mtwalume Farmers Association, [Online], [Cited: 6 June 2010], Available: http://www.scga.co.za/docs/dirkhibbnov10.pdf.

[31] Mudavanhu P, 2010, PhD Candidate in the Department of Conservation Ecology and Entomology at Stellenbosch University, [Personal Communication], Contactable: mudavanhu@sun.ac.za.

[32] Murray JD, 2002, Discrete population models for a single species, pp. 44-78 in Antman SS, MarsDEN JE, Sirovich L \& Wiggins S (EDs), Mathematical biology, I: An introduction, Springer, New York (NY).

[33] North DT, 1975, Inherited sterility in lepidoptera, Annual Review of Entomology, 20, pp. 167-182.

[34] PANnell DJ, 1997, Sensitivity analysis of normative economic models: Theoretical framework and practical strategies, Agricultural Economics, 16, pp. 139-152.

[35] Paxton RH, 1982, Eldana borer (Eldana Saccharina): The results of surveys, Proceedings of the South African Sugar Technologists Association, 56, pp. 99-103.

[36] Potgieter L, In prep., A mathematical model for the control of Eldana saccharina Walker via the sterile insect technique, PhD Dissertation, Stellenbosch University, Stellenbosch.

[37] Proverbs MD, 1969, Induced sterilization and control of insects, Annual Review of Entomology, 14, pp. 81-102.

[38] Rendon P, McInnis D, Lance D \& Stewart J, 2004, Medfly (Diptera: Tephritidae) genetic sexing: Large-scale field comparison of males-only and bisexual sterile fly releases in Guatemala, Journal of Economic Entomology, 97(5), pp. 1547-1553.

[39] Sampson MA \& Kumar R, 1985, Life history, development and behaviour of Eldana saccharina Walker on sugarcane in Southern Ghana, Insect Science and its Application, 6(2), pp. 135-143. 
[40] Stotter R, 2011, Quality and Technical Manager at Xsit (Pty) Ltd, [Personal Communication], Contactable: rob@xsit.co.za.

[41] TAN LT \& TAN KH, 2011, Alternative air vehicles for sterile insect technique aerial release, Journal of Applied Entomology, 135(8), DOI: 10.1111/j.1439-0418.2011.01649.x.

[42] VAN COLLER LM, 1992, Optimum biological control strategies for a problem in the sugar industry A mathematical modelling approach, MSc Thesis, University of Natal, Pietermaritzburg.

[43] Walton AJ, 2011, Radiation biology of Eldana saccharina Walker (Lepidoptera: Pyralidae), MSc Thesis, Stellenbosch University, Stellenbosch.

[44] Way MJ, 1995, Developmental biology of the immature stages of Eldana saccharina Walker (Lepidoptera: Pyralidae), Proceedings of the South African Sugar Technologists Association, 69, pp. 83-86.

[45] Way MJ, 2001, Characteristics of sugarcane bored by Eldana saccharina Walker (Lepidoptera: Pyralidae), Proceedings of the South African Sugar Technologists Association, 75, pp. 257-257.

[46] Webster TM, Maher GW \& Conlong DE, 2005, An integrated pest management system for eldana saccharina in the Midlands North region of KwaZulu-Natal, Proceedings of the South African Sugar Technologists Association, 79, pp. 347-358.

[47] Wohlfarter M, 2011, Manager at Entomon Technologies (Pty) Ltd, [Personal Communication], Contactable: martin@entomon.co.za. 